\title{
Sejarah Tradisi Sendang Dan Nilai Sosial-Religius Desa Tetep Kelurahan Randuacir Kecamatan Argomulyo Kota Salatiga
}

\author{
Aida Fitriyani, Tri Widiarto, Sunardi \\ Program Studi Pendidikan Sejarah, FKIP, Universitas Kristen Satya Wacana Salatiga \\ Email: aidafitriyani99@gmail.com
}

\begin{abstract}
Abstrak: Sendang merupakan sumber air yang tidak pernah mengalami kekeringan. Kebanyakan sendang di tanah Jawa bersifat sakral serta di hormati. Di Desa Tetep sendang adalah tempat yang di sakralkan dan di hormati dengan melaksanakan tradisi atau upacara adat. Tradisi Sendang di Desa Tetep dilakukan pada dua sendang yang biasa disebut dengan sendang Ki Godong mPlati, Nyi Godong mPlati, dan Ki Gambreng. Tradisi ini dilaksanakan oleh masyarakat Desa Tetep saat mengadakan acara besar. Tradisi Sendang dilaksanakan bertujuan untuk menghormati dan meminta kelancaraan acara tersebut kepada Yang Maha Esa melalui perantara sendang. Tujuan penelitian ini untuk mengetahui makna dan nilai sosial-religius yang terdapat pada tradisi sendang pada masyarakat Desa Tetep. Metode penelitian yang digunakan adalah wawancara, observasi, dokumentasi, dan kajian pustaka. Hasil penelitian ini mengambarkan tatacara pelaksanaan tradisi sendang di Desa Tetep. Pelaksanaan tradisi menjadi pelestarian budaya lokal. Tradisi ini mengandung mitos turuntemurun yang dipercaya masyaratkat Desa Tetep. Mitos yang di implementasikan dalam budaya inilah yang membuat Tradisi Sendang mengandung nilai sosial-religius.
\end{abstract}

\section{Kata Kunci: Sosial, Religius, Tradisi, Sendang, Desa Tetep}

\begin{abstract}
Sendang is a water source that has never experienced drought. Most spring in Java is sacred and respected. In the village of Tetep Sendang is a place that is sacred and respected by carrying out traditions or traditional ceremonies. The tradition of Sendang in Tetep Village is carried out on two springs, commonly called the Ki Godong mPlati, Nyi Godong mPlati, and Ki Gambreng. This tradition is carried out by the people of Tetep Village when holding a big event. The tradition of Sendang is carried out with the aim of honoring and requesting the smooth running of the event to the Almighty through the intermediary Sendang. The purpose of this study was to determine the social-religious meaning and values contained in the spring tradition in the Tetep Village community. The research methods used were interviews, observation, documentation, and literature review. The results of this study illustrate the procedure of implementing spring tradition in Tetep Village. The implementation of tradition becomes the preservation of local culture. This tradition contains hereditary myths believed by the people of Tetep Village. The myths that are implemented in this culture make the Sendang Tradition contain social-religious values.
\end{abstract}

Keywords: Social, Religious, Tradition, Sendang, Tetep Village

\section{Pendahuluan}

Dalam masa globalisasi yang sudah menyebar ke seluruh penjuru dunia, Indonesia adalah salah satu negara yang masih menjaga kesakralan budaya lokal. Budaya di Indonesia sangat beragam yang terbentuk dari banyak unsur yang rumit, termasuk sistem agama dan politik, adat istiadat, bahasa, perkakas, pakaian, bangunan, dan karya seni (Koentjaraningrat, 1990). Seorang yang berusaha berkomunikasi dengan orangorang yang berbeda budaya akan menyesuaikan perbedaan-perbedaannya dan membuktikan bahwa budaya itu dipelajari (Sulasman, 2013). Budaya sangat penting dan berarti bagi masyarakat. Nilai dan norma yang ada didalam budaya 
tersebut diterapkan dalam kehidupan masyarakat sehari-hari yang diwariskan secara turun-temurun. Budaya adalah suatu pola hidup menyeluruh, bersifat kompleks, abstrak, dan luas. Budaya adalah suatu cara hidup yang berkembang dan dimiliki bersama oleh sekelompok orang dan diwariskan turun-temurun atau generasi ke generasi. Budaya terbentuk dari banyak unsur yang rumit, termasuk sistem agama dan politik, adat istiadat, bahasa, perkakas, pakaian, bangunan, dan karya seni. Seorang yang berusaha berkomunikasi dengan orang-orang yang berbeda budaya akan menyesuaikan perbedaan-perbedaannya, dan ini membuktikan bahwa budaya itu dipelajari (Sulasman, 2013). Kebudayaan adalah keseluruhan sistem gagasan, tindakan, dan hasil karya manusia dalam rangka kehidupan masyarakat yang dijadikan milik diri manusia dengan belajar (Koentjaraningrat, 2000).

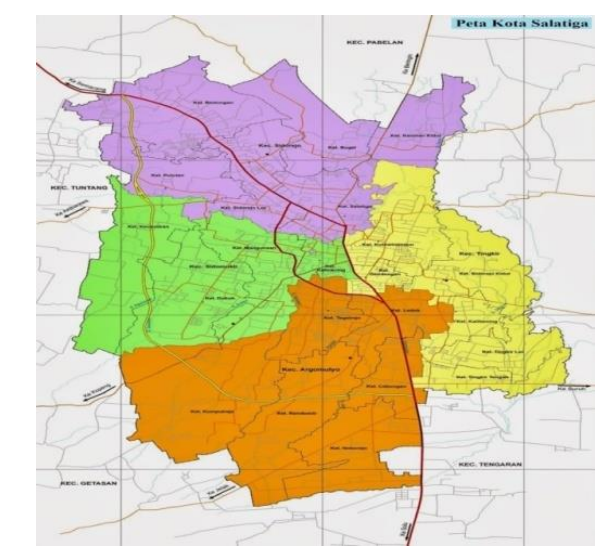

Gambar 1. Peta Kota Salatiga

(Dokumentasi Mading Kelurahan Randuacir) Desa Tetep Kelurahan Randuacir Kecamatan Argomulyo Kota Salatiga Jawa
Tengah Indonesia merupakan desa yang sangat menjaga tradisi. Desa Tetep ini memiliki wilayah yang rindang penuh dengan pepohonan, udara sejuk, dan masyarakat yang ramah. Desa Tetep sangat terkenal dengan tradisi leluhur yang masih dilaksanakan hingga sekarang. Tradisi yang masih dilaksanakan hingga sekarang yaitu tradisi sendang.

Sendang merupakan sumber air yang tidak pernah mengalami kekeringan namun di sakralkan oleh masyarakat setempat. Meskipun sendang adalah sumber air, masyarakat Desa Tetep tidak selalu mengambil air setiap hari kecuali musim kemarau atau kekeringan. Tradisi sendang dilaksanakan setiap masyarakat akan mengadakan acara besar seperti pernikahan, pengajian, reogan, khitanan, yang terkait dengan siklus hidup manusia.

Sejarah Tradisi sendang pertama kali dilakukan oleh juru kunci pertama Tradisi Sendang yang disebut masyarakat setempat dengan nama Marni. Marni adalah perias pengantin (dukun nganten) yang kental dengan hawa mistis. Pertama kali ada bencana untuk Desa Tetep yaitu adanya 7 orang meninggal dalam seminggu berturut-turut. Marni berkata kepada masyarakat untuk mengadakan perawatan Sendang di Desa Tetep dengan menguri-uri atau merawat Sendang maka, akan menyingkirkan bala atau musibah di Desa Tetep. Sehingga Tradisi Sendang ini berlangsung hingga sekarang. Tradisi 
sendang dilaksanakan di dua tempat. Dua sendang tersebut dipercaya oleh masyarakat dijaga oleh roh leluhur dan di beri nama. Pertama, di sendang yang di kenal sebagai Ki Godong mPlati, Nyi Godong mPlati. Masyarakat percaya jika penunggu sendang pertama adalah sepasang suami dan istri atau ditunggu oleh dua orang yang dilambangkan sebagai siwur atau gayung yang dikelilingi pohon beringin dan dekat sengan sungai.

Kedua, di sendang yang dikenal dengan sebutan Ki Gambreng. Masyarakat peracaya jika sendang kedua di tunggu oleh seorang sesepuh yang dilambangkan sebagai bak atau tempat air yang dekat dengan sungai dikelilingi pohon bambu yang sejuk. Masyarakat mengenal dua sendang tersebut dengan nama manusia karena mereka percaya bahwa penunggu sendang yaitu roh leluhur. Tradisi sendang di Desa Tetep berbeda dengan tradisi wilayah lain. Biasanya masyarakat hanya mengimplementasikan rasa syukur dengan kenduri atau merti desa saja, tanpa melakukan tradisi di sendang secara khusus. Tujuan penelitian untuk menelaah sejarah tradisi sendang dan nilai sosialreligius pada masyarakat Desa Tetep.

\section{Metode}

Lokasi penelitian yang dipilih oleh peneliti yaitu di Desa Tetep Kelurahan Randuacir Kecamatan Argomulyo Kota Salatiga Jawa Tengah. Lokasi tersebut adalah lokasi yang menyelenggarakan tradisi sendang Ki Godong mPlati, Nyi Godong mPlati, dan Ki Gambreng yang mengandung nilai-nilai karakter sosialreligius masyarakat Desa Tetep. Metode yang digunakan adalah metode kualitatif. Metode kualitatif sering dikenal sebagai metode naturalistik karena penelitiannya dilakukan pada kondisi yang alamiah, disebut juga metode etnografi.

Oleh sebab awalnya metode ini lebih banyak digunakan untuk penelitian bidang antropologi budaya, disebut juga sebagai metode kualitatif karena data yang dikumpulkan dan dianalisis lebih bersifat kualitatif. Dalam metode penelitian kualitatif, sumber data dipilih secara purposive dan bersifat snowball sampling. Menggunakan dua sumber data yaitu sumber data primer, sumber data ini meliputi observasi dan wawancara dan skunder, sumber data ini meliputi studi kepustakaan, dan arsip benda-benda yang terkait dalam penelitian (Sugiyono, 2013).

Teknik pengumpulan data dilakukan secara triangulasi (gabungan) adalah teknik pengumpulan data dan sumber data yang telah ada. Peneliti mengumpulkan data sekaligus menguji data yang ada mengunakan teknik yang berbeda-beda untuk mendapatkan data dari sumber yang sama. Peneliti menggunakan observasi partisipatif, wawancara mendalam, dan dokumentasi untuk sumber data yang sama secara 
serentak (Sugiyono, 2013), analisis data bersifat induktif atau kualitatif, dan hasil penelitian kualitatif lebih menekankan makna dari generalisasi, yaitu: studi pustaka berupa kajian peneliti terdahulu seperti buku tentang sejarah, buku tentang tradisi budaya jawa, dan buku tentang penelitian (Sugiyono, 2013), Observasi dengan cara melihat, mengamati, dan mencerna pelaksanaan Tradisi Sendang yang sedang berlangsung (Herdiansyah, 2013),

Wawancara dilakukan langsung kepada juru kunci sendang dan msayarakat yang secara langsung melaksanakan Tradisi Sendang (Herdiansyah, 2013), serta dokumentasi dengan cara mengumpulkan foto pelaksanaan Tradisi Sendang (Sugiyono, 2013). Data yang dikumpulkan berupa kata-kata, gambar, dan bukan angka. Dengan metode penelitian kualitatif maka diharapkan peneliti bisa menjadi kunci dari penelitian yang diadakan dalam Tradisi Sendang Ki Godong mPlati, Nyi Godong mPlati, dan Ki Gambreng untuk mengetahui secara mendalam nilai social dan religius.

Setelah mengetahui nilai yang terkandung dalam Tradisi Sendang maka data penelitian harus di validasi menggunakan triangulasi data. Triangulasi data adalah teknik pengumpulan data dan sumber data yang telah ada. Peneliti mengumpulkan data sekaligus menguji data yang ada mengunakan teknik yang berbeda-beda, guna mendapatkan data dari sumber yang sama. Peneliti menggunakan observasi partisipatif, wawancara mendalam, dan dokumentasi untuk sumber data yang sama secara serentak.

\section{Hasil Dan Pembahasan}

\section{A. Sejarah dan Pelaksanaan Tradisi Sendang}

Tradisi Sendang Ki Godong mPlati, Nyi Godong mPlati, dan Ki Gambreng merupakan kebudayaan atau adat kebiasaan yang dijalankan atau diwariskan secara turun-temurun oleh masyarakat Desa Randuacir khususnya Dusun Tetep. Tradisi ini dilakukan sewaktu-waktu tanpa ada tanggal atau bulan yang tetap. Tradisi ini dilaksanakan setiap adanya hajat atau acara masyarakat misalnya, pernikahan, syukuran dan khitanan. Tradisi Sendang Ki Godong mPlati, Nyi Godong mPlati, dan Ki Gambreng tidak luput dari leluhur.

Nama yang ditulis dengan huruf $m$ kecil dan huruf $\mathrm{p}$ kapital menandakan penekanan bahasa dalam tutur kata Jawa. Masyarakat Desa Tetep Randuacir masih percaya animisme dan dinamisme. Dahulu pohon beringin dan sumber air dipercaya sebagai sumber kehidupan dan mengandung sumber magis. Letak sendang atau sumber air Ki Godong mPlati, Nyi Godong mPlati dan Ki Gambreng masingmasing dikelilingi oleh pohon beringin. Sehingga masyarakat setempat menghargai tempat tersebut dengan cara memberikan 
sesaji jika masyarakat ada yang mempunyai acara. Menurut masyarakat setempat terdapat manfaat tradisi Sendang. Pertama, dapat melestarikan budaya atau tradisi yang tidak dimiliki Desa lainnya, Kedua, mendapatkan keselamatan dan kelancaran saat acara yang diadakan oleh masyarakat setempat lancar tanpa halangan apapun, dan Ketiga, mempererat tali persaoudaraan dan menjalin kerukunan antar warga.

Oleh karena pada saat tradisi Sendang Ki Godong mPlati, Nyi Godong mPlati, dan Ki Gambreng akan dilaksanakan banyak masyarakat yang saling gotong-royong membantu untuk melancarkan tradisi tersebut walaupun yang menata sesaji dan doa harus juru kunci sendang. Masyarakat menggangap bahwa sendang tersebut sebagai leluhur mereka yang disebut dengan nama $\mathrm{Ki}$ Godong mPlati, Nyi Godong mPlati, dan Ki Gambreng.

Masyarakat mengangap bahwa jika mereka punya hajat, sendang juga harus ikut merasakan karena hajad biasanya adalah acara yang mengembirakan untuk masyarakat maka leluhur mereeka juga harus merasakan kegembiraan. Tradisi Sendang Ki Godong mPlati, Nyi Godong mPlati dan Ki Gambreng ini dilaksanakan dengan tujuan untuk menghormati leluhur dan melaksanakan tradisi atau adat kebudyaan yang sudah dilaksanakan turuntemurun. Masyarakat percaya bahwa melaksanakan tradisi ini acara atau hajad yang dilaksanakan berjalan dengan lancar dan sesuai rencana. Jika tidak melaksanakan masyarakat percaya, ada bencana sebelum atau sesudah hajat dilaksanakan.

Masyarakat Desa Tetep Randuacir masih percaya adanya animisme dan dinamisme. Hal ini tidak semata-mata hanya dianggap mitos tetapi pernah dibuktikan oleh beberapa orang yang menggangap hal ini remeh dan akibatnya orang tersebut mendapatkan bencana atau bala diacara yang mereka adakan (wawancara dengan Jumali, 23 Juni 2016).

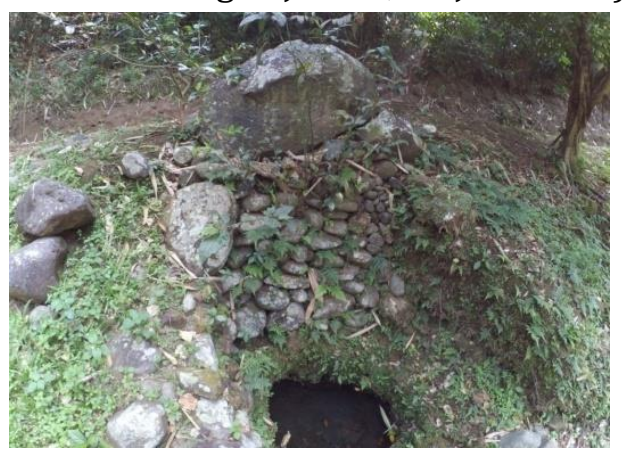

Gambar 2. Sendang Ki Gambreng (Dokumentasi Pribadi, 2019)

Maka dari itu Tradisi Sendang Ki Godong Mplati, Nyi Godong Mplati, dan Ki Gambreng masih dilaksanakan oleh masyarakat Desa Tetep Randuacir untuk memperoleh keselamatan. Bahkan jika tradisi ini tidak dilaksanakan maka masyarakat tidak berani mengadakan hajadan pernikahan, syukuran, ataupun khitanan dan yang lainnya.

Sebelum dilaksanakan tradisi Sendang Ki Godong Mplati, Nyi Godong 
Mplati dan Ki Gambreng warga yang memiliki hajat atau acara harus membentuk panitia acara atau bahasa Jawanya angkroh. Panitia terdiri atas ketua biasanya ketua RT, wakil ketua, perangkat desa, sesepuh desa, juru kunci sendang dan angota panitia. Panitia mempersiapkan hajat yang akan dilaksanakan oleh tuan rumah sekaligus menyiapkan berbagai makanan yang diberikan juru kunci sendang.

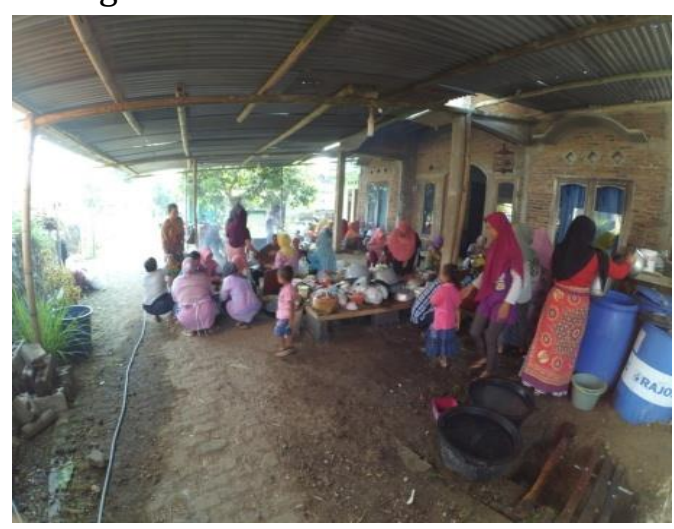

Gambar 3. Proses Masyarakat Mengadakan Persiapan Upacara Sendang (Dokumentasi pribadi, 2019)

Makanan ini terdiri dari ingkung ayam, buah nanas, timun, buah pisang raja, ketupat, nasi ketan hitam dan nasi ketan putih, berondong, buah bengkoang, gethok, kacang, bubur jenang roti, tape nasi ketan hitam, tiwul, cenil, mendut, sambel urap, sambel gepeng, cengkaruk, jenang blowok dan sayur limaran. Tidak hanya jajanan atau makanan saja namun, juga beberapa hal yang harus dipersiapkan tuan rumah yang memiliki hajat. Diantaranya daun dadap, daun awar-awar, daun alang-alang, buah kedondong, keetupat, parem, kain jarik, paku, janur atau daun pohon kelapa yang muda berjumlah 10 , air putih, teh, kopi, rokok, bunga setaman, wangiwangian, uang receh, kendi, bdan besek atau tempat yang terbuat dari bambu.

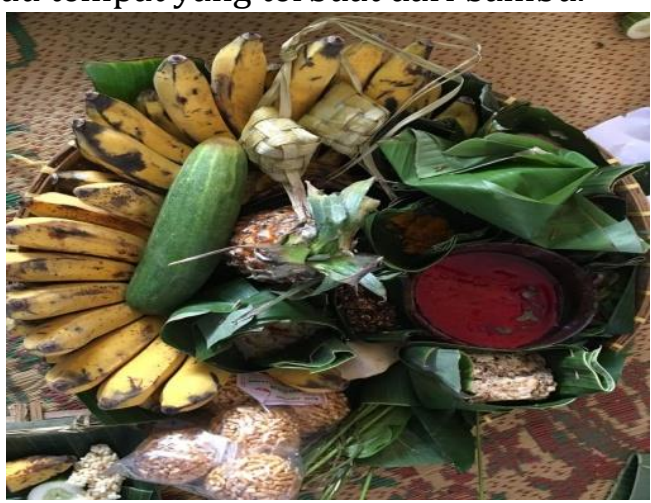

Gambar 4. Sesaji Persembahan Sendang

(Dokumentasi pribadi, 2019)

Pelaksanaan tradisi Sendang Ki Godong mPlati, Nyi Godong mPlati, dan Ki Gambreng apabila warga atau masyarakat memiliki hajat atau acara misalkan pernikahan, syukuran, merti desa, saparan, khitanan dan lain-lain. Kegiatan ini dimulai pada pagi hari dan satu hari sebelum acara dilaksanakan. Tradisi Sendang Ki Godong mPlati, Nyi Godong mPlati, dan Ki Gambreng dipersiapkan oleh juru kunci sekitar pukul 10.00 WIB untuk menata makanan atau masyarakat menyebutnya jajanan yang terdiri atas 5 buah tatanan atau sesajen dan tatanan dirumah yang berurutan. Pertama, tolak balak rumah atau menolak keburukan yang akan menimpa pemilik hajad yaitu menyiapkan janur yang disilangkan lalu dipasang dengan 10 paku di berbagai sisi rumah warga yang memiliki hajad. Sisi rumah yang dipasangi oleh janur 
yaitu depan pintu rumah, sisi samping rumah dan sisi belang rumah.

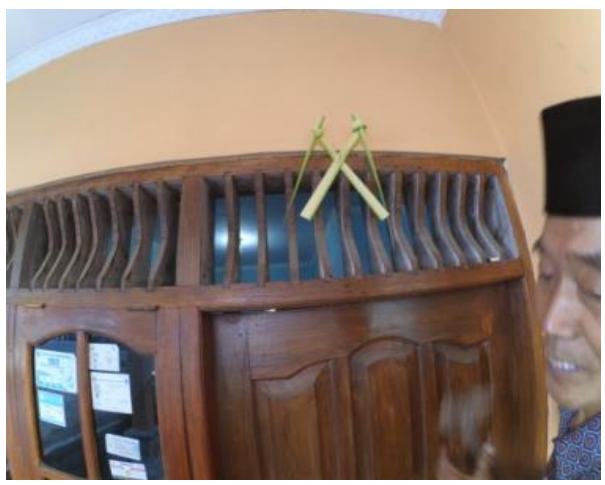

Gambar. 5 Janur Penolak Balak

(Dokumentasi pribadi, 2019)

Selain menolak bala` dengan menempelkan janur di setiap sisi rumah, menolak hajat juga mengaitkan tempat air atau yang biasa disebut dengan genthong oleh masyarakat Desa Tetep Randuacir menggunakan kain jarik yang diikat janur. Kemudian diikatkan ke gentong atau tempat air yang digunakan untuk memasak, yang selama penelitian berlangsung, acara yang dilaksanakan masyarakat Desa Tetep Randuacir adalah pernikahan.

Kedua, tatanan pertama berbentuk besar berisi daun pisang untuk alas, nasi tumpeng di tengah, ayam ingkung, pisang raja 1 lirang, darah ayam, bunga setaman, sambel urap, sambel gepeng, cengkaruk, parem, jenang blowok, nasi ketan putih, nasi ketan hitam, sayur limaran, daun dadap, daun awar-awar, daun alang-alang, timun, buah kedodong, ketupat, air putih, kopi, teh dan buah nanas yang mengelilingi nasi tumpeng. Ketiga, tatanan yang kedua, ketiga, dan keempat biasanya disebut tambir kecil yang berisi daun pisang untuk alas, tumpeng nasi berukuran kecil, uang, kinang, rokok, kendi berisi air putih, bunga setaman dan menyan dalam satu wadah kecil, cengkaruk, daging sapi yang sudah masak, dan sawut klopo atau parutan daging kelapa yang mengelilingi nasi tumpeng kecil. Jika tatanan dan tolak bala` selesai maka, tatanan sebelum dibawa kesendang didoakan terlebih dahulu oleh juru kunci bersama masyarakat Desa Tetep Randuacir.

Setelah acara do`a untuk keselamatan maka dilanjutkan dengan makan bersama masyarakat. Setelah makan bersama masyarakat bersama juru kunci melakukan iring-iringan menggunakan kendaran bermotor untuk menuju sendang Ki Godong Mplati dan Nyi Godong Mplati. Lalu dipimpin oleh juru kunci sendang untuk melakukan upacara menyerahan sesaji atau tatanan yang di sebut tambir dan di do`akan bersama kembali oleh warga yang ikut melaksanakan tradisi tersebut.

Dua tambir diletakan dibawah pohon beringin tepat disebelah sendang $\mathrm{Ki}$ Godong mPlati, Nyi Godong mPlati. Selesai dari Sendang Ki Godong mPlati, Nyi Godong mPlati lalu masyarakat menuju sendang Ki Gambreng mengadakan upacara do`a bersama yang dipimpin oleh juru kunci. Sesaji atau tambir kemudian diletakkan diatas sendang, tepatnya diatas batu. Setelah acara selesai masyarakat kembali kerumah warga yang mengadakan acara 
pernikahan lalu tambir besar yang pertama diletakan di kamar pengantin oleh juru kunci sendang.

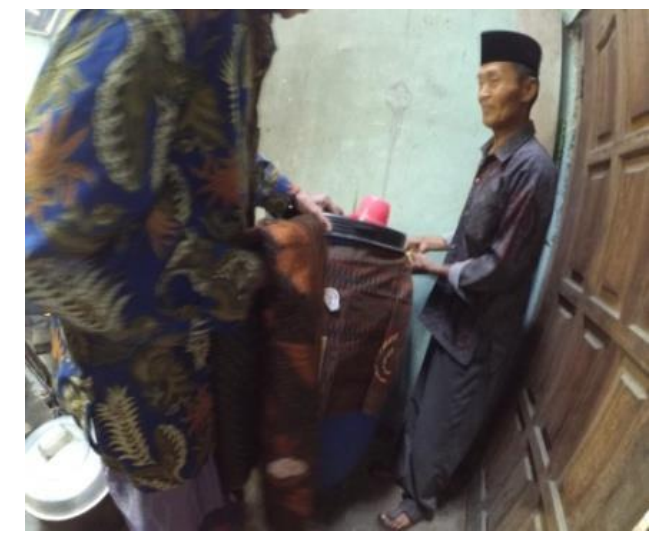

Gambar. 6 Pengikatan Kain Jarik

(Sumber: dok. Aida Fitriyani)

\section{B. Makna Sosial dan Religius Pada} Tradisi Sendang

Setiap komponen dalam tradisi pasti memiliki maksud dan tujuan. Seperti komponen yang ada dalam setiap sesaji atau tambir dalam tradisi sendang ini seperti tumpeng nasi putih yang memiliki arti bahwa yang paling tinggi, paling bersih, dan paling suci hanya Tuhan semata. Bunga setaman dan menyan dianggap sebagai sesembahan untuk leluhur. Daging sapi dilambangkan sebagai diri manusia yang berbeda dari mahluk lain dan diserahkan sepenuhnya untuk Tuhan yang Esa. Ingkung ayam dilambangkan sebagai sifat manusia yang harus tunduk kepada Tuhan. Dan komponen lain yang disebut jajanan atau makanan pasar diperlambangkan sebagai pelengkap kehidupan manusia saat ini. Selanjutnya nilai merupakan sesuatu yang diinginkan dan dicita-citakan apabila sesuatu itu baik, adil dan berguna sehingga memunculkan ungkapan yang bernilai (Purwadi, 2005). Dalam pelaksanaan tradisi Sendang terdapat nilai sosial, yaitu kekeluargaan. Hal ini tampak pada pelaksanaan tradisi sendang $\mathrm{Ki}$ Godong mPlati, Nyi Godong mPlati dan Ki Gambreng pada pagi hari, warga berdatangan tanpa diundang oleh orang yang memiliki acara. Warga sekaligus membantu acara tersebut tanpa dibayar sekalipun. Lalu nilai selanjutnya adalah gotong royong.

Dibuktikan ketika warga yang datang ke acara hajatan saling membantu untuk belanja makanan untuk sesembahan sendang, membersihan sendang dan mendirikan atap sementara untuk acara hajatan atau pernikahan warga. Sedangkan nilai religius yang terdapat pada tradisi sendang yaitu adanya do`a bersama sebelum datang maupun saat datang ke sendang. Kemudian menghormati leluhur dengan melaksanakan tradisi di sendang untuk mengingat atau penghormatan leluhur, dengan memberikan sesaji atau tambir yang diletakan di setiap sudut sendang Ki Godong mPlati, Nyi Godong mPlati dan Ki Gambreng.

Masyarakat percaya jika tidak melaksanakan tradisi sendang maka, terkena bencana. Hal ini tidak di dasari oleh pembicaraan saja. Dulu pernah ada masyarakat yang mengadakan acara pernikahan tidak melakukan tradisi sendang dan orang itu menjadi sial, 
terpotongnya tangan kiri pemilik acara tersebut. Bukan hanya itu, masyarakat pernah mengadakan acara umum yaitu memangil seni tari reog dan ada masyarakat Desa Tetep yang meninggal. Tradisi sendang dilakukan untuk menolak bala', dan meminta kelancaran kepada roh penunggu sendang yang di percaya masyarakat setempat dengan sebutan $\mathrm{Ki}$ Godong mPlati, Nyi Godong mPlati, dan Ki Gambreng. Rasa syukur telah diungkapkan oleh masyarakat Desa Tetep Randuacir yang mampu melaksanakan acara hajadan pernikahan dan berbagai rasa syukur itu untuk leluhur mereka. Merasa tentram jika melaksanakan tradisi sendang masyarakat sehingga tidak khawatir ketiak acara hajatan pernikahan berlangsung

Dengan pelaksanaan tradisi $\mathrm{Ki}$ Godong Mplati, Nyi Godong Mplati, dan Ki Gambreng yang dilaksanakan secara turuntemurun dan setiap komponen tidak boleh digantikan. Oleh karena yang dipercaya bahwa sesuai aturan acara hajatan yang dilaksanakan oleh warga Desa Tetep memberi kelancaran acara dan sesuai harapan mereka. Selain menghormati leluhur dan meminta keselamatan tradisi sendang juga terdapat fungsi lain yaitu guna mengingatkan manusia bahwa Tuhan tetap yang paling tinggi dan masyarakat tidak meninggikan hal lain selain Tuhan yang Esa. Oleh karena kebiasaan tersebut sudah tertanam bagi masyarakatnya (Melianti \& Wibowo, 2019).

\section{Kesimpulan}

Sesuai hasil penelitian, analisis dan pengumpulan data yang sudah dipaparkan pada kajian tersebut dapat diambil kesimpulan bahwa Pertama, tradisi sendang berbeda dengan tradisi yang ada di daerah lain. Tradisi yang berada di Desa Tetep ini mengandung tradisi pernikahan, tradisi saparan, merti dusun dan sebagainya yang harus dilakukan di tradisi sendang. Tradisi sendang termasuk dalam tradisi yang wajib dijalankan sebagai langkah awal sebelum melaksanakan tradisi yang lainnya.

Tradisi Sendang dilakukan dengan tujuan untuk meminta keselamatan, kelancaran dan ketenangan sebelum melaksanakan upacara tradisi yang lain. Tradisi Sendang cukup sakral karena mengandung nilai mitos yang telah turuntemurun dalam masyarakat setempat. Tradisi ini mengandung komponenkomponen yang banyak yang harus dikaji secara lebih rinci. Sehingga perlu ada ikut campur tangan pemerintah dengan melibatkan stakeholder dinas pariwisata guna mempromosikan budaya Kota Salatiga khususnya Desa Tetep dari wisatawan lokal maupun asing. Selain itu perlu juga melibatkan pemuda sehingga internalisasi tadisi ini dapat berjalan secara turun-temurun.

\section{Daftar Pustaka}

Herdiansyah, H. (2013). Wawancara Observasi dan Fokus Groups Sebagai 
Instrumen Penggalian Data Kualitatif. Jakarta: Rajawali.

Koentjaraningrat. (1990). Sejarah Teori Antropologi II. Jakarta: Universitas Indonesia.

Koentjaraningrat. (2000). Pengantar Ilmu Antropologi. Jakarta: Rineka Cipta.

Melianti, E., \& Wibowo, A. M. Peran Perempuan Papua Dalam Peningkatan Ekonomi Keluarga di Kelurahan Wonosari Jaya Distrik Wania (Nilai Budaya dan Potensinya Sebagai Sumber Pembelajaran IPS SMP). Gulawentah: Jurnal Studi Sosial, 4(2), 78-84.

http://doi.org/10.25273/gulawentah. v4i2.5523

Purwadi. (2005). Upacara Tradisional Jawa. Yogyakarta: Pustaka Pelajar.

Sugiyono. (2013). Metode Penelitian Kuantitatif, Kualitatif, Dan R\&D. Bandung: Alfabeta.

Sulasman. (2013). Teori-teori Kebudayaan. Bandung: Pustaka Setia. 